\title{
Screening for COVID-19 in Older Adults: Pulse Oximeter vs. Temperature
}

\author{
Catherine R. Van Son ${ }^{1 *}$ and Deborah U. Eti ${ }^{2}$ \\ ${ }^{1}$ College of Nursing, Washington State University-Vancouver, Vancouver, WA, United States, ${ }^{2}$ College of Nursing, \\ Washington State University-Spokane, Spokane, WA, United States
}

Keywords: older adults, COVID-19, silent hypoxia, temperature, pulse oximeter, atypical presentation

\section{INTRODUCTION}

Public health screening for COVID-19 and its mutations are becoming a routine activity, as we assess the safety of resuming interactions with each another. Control efforts have included social distancing, hygiene, masks, and lockdowns. Where available, testing can confirm exposure to COVID-19. Prior to testing, screening is conducted, typically consisting of assessing one's temperature and asking questions related to symptoms and exposures. However, the efficacy of symptom-based screening (temperature and self-report) for COVID-19 has been called into question in recent studies for both the general population and healthcare workers $(1,2)$. Older adults are another population in which symptom-based screening for COVID-19 should be questioned.

As the pandemic unfolded, older adults have been hardest hit. The statistics are staggering, with older adults making up $45-80 \%$ of all hospitalizations, $53 \%$ of intensive care admissions, and $80 \%$ of deaths $(3,4)$. However, the media's tone has been that this was not alarming but expected due to age and comorbidities. This paper offers suggestions to mitigate these statistics.

\section{TEMPERATURE AND OLDER ADULTS}

Neftali Eduardo Antonio-Villa,

The presence of fever is a key clinical indicator of infection and inflammation (5). Thus, the initial objective screening for COVID-19 has been using temperature measurements to diagnose the presence of infection. Of the general population, $98 \%$ of the COVID-19 patients was found to have a fever, along with other symptoms (6).

Fever is defined as a temperature of $100.4^{\circ} \mathrm{F}\left(38.0^{\circ} \mathrm{C}\right)$ or greater $(4)$. However, studies have found that older adults show a lower core body temperature, described as below $98.6^{\circ} \mathrm{F}\left(36.4^{\circ} \mathrm{C}\right)$, using the standard definition of a fever is a less useful indicator of infection with older adults $(7,8)$. Other studies have found that baseline temperatures may be as low as $94^{\circ} \mathrm{F}\left(34.4^{\circ} \mathrm{C}\right)$ for older adults (9). In a study of 35,488 participants with a mean age of 52.9 years, the baseline temperatures declined with age $\left(-0.02^{\circ} \mathrm{C}\right.$ every decade, $\left.p<0.001\right)(10)$. In a sample of 18,630 (aged $20-98$ years) with a mean age 58.0 years with equal numbers of male/female participants, researchers found an average basal oral body temperature of $97.3^{\circ} \mathrm{F}\left(36.2^{\circ} \mathrm{C}\right)$ (11). A study of 2410 hospitalized patients with influenza aged $\geq 65$ years found a lower temperature threshold $99^{\circ} \mathrm{F}\left(\geq 37.2^{\circ} \mathrm{C}\right)$ and captured $78 \%$ of influenza-positive individuals, while the CDC's threshold for a fever $100^{\circ} \mathrm{F}\left(37.8^{\circ} \mathrm{C}\right)$ captured only $57 \%(12)$.

Lower baseline temperatures may result in overlooking fevers. In fact, upwards of $30 \%$ of older adults with serious infections show a mild or no fever $(7,13)$. One study found older adults $(N=1,318)$, presented to the emergency department with influenza $2-5$ days after symptom onset (14). In other studies, seeking treatment occurred up to 1 week after symptom onset $(15,16)$. This 
delay in seeking health care increases their mortality risk (14). Therefore, the objective measure of a temperature and the threshold of $100.4 \mathrm{~F}$ as a fever indicator does not provide a sufficient indicator of infection in older adults and may delay the diagnosis and treatment for COVID-19 $(15,16)$.

\section{ATYPICAL PRESENTATION OF COVID-19 IN OLDER ADULTS}

Similar to a fever, older adults lack other usual signs and symptoms of illness onset or exacerbation. Atypical presentations could just be a change in cognitive status or mobility. COVID19 symptoms include fatigue, body aches, weakness and an increasing loss of taste and smell (17). Each of these symptoms may be dismissed as a normal part of aging. Other symptoms, such as coughing, or shortness of breath may be normal for existing chronic conditions such as chronic obstructive pulmonary disease (COPD) or congestive heart failure (CHF). Older adults with COVID-19 do show typical symptoms such as shortness of breath, fever, and cough; however, many of them do not (17). Atypical presentations of COVID-19 in older adults include a delay in fever and respiratory symptoms. COVID-19 symptoms may present themselves anywhere from $4-5$ to 14 days after exposure, which may be too late for initiating interventions and having positive outcomes (18).

\section{SILENT HYPOXIA}

In April 2020, an emergency room doctor observed COVID-19 patients without visible signs of dyspnea and a $\mathrm{SpO}_{2}$ below $90 \%$. He noticed that these patients had a form of oxygen deprivation, which is difficult to detect, called "silent hypoxia," despite the patients feeling alert and breathing normally (19).

Asymptomatic hypoxia (AH) or silent hypoxia is becoming more prevalent in the COVID-19 literature and is associated with extremely poor outcomes (20). In many cases, $\mathrm{AH}$ is associated with a delay in care as the presence of hypoxemia is not identified in the absence of dyspnea (21). In a study from prehospital first responder data, a higher discrepancy was found between oxygen saturation $\left(\mathrm{SpO}_{2}\right)$ and respiratory rates in COVID-19 Acute Respiratory Failure (ARF) patients compared to earlier non-COVID-19 ARF patients (22). Without an $\mathrm{SpO}_{2}$ measurement, normal breathing rates could mask profound hypoxia and make the assessment of severity more difficult in an out-of-hospital setting.

Providers must remain attentive while checking for a 3-5\% drop in $\mathrm{SpO}_{2}$ after mild activity/ambulation, room air, and the presence of hypoxemia without tachypnea $(19,21)$. However, these symptoms may not be occurring in a clinical setting but at home. For this, there is a portable device: the pulse oximeter, which may detect "silent hypoxemia" in older adults with COVID-19, to be used at home or in a community seniorliving setting (22).

\section{PULSE OXIMETERS}

Pulse oximeters are a noninvasive and painless device that measures oxygen saturation levels in the blood (22). COVID19 pandemic studies are finding increasing value in using pulse oximetry devices. Studies include the usefulness of oximeters in low-resource settings and predicting clinical deterioration $(23,24)$. A study evaluating 22 prognostic models for COVID19 found peripheral oxygen saturation on room air and age was a predictor of clinical deterioration and mortality. In addition, the authors recommended that oximeters should be used in initial screenings as well as community-based monitoring (24).

Given its potential efficacy for detecting changes in $\mathrm{SpO}_{2}$, pulse oximeters should be considered to screen for COVID-19 $\mathrm{AH}$ in older adults $(25,26)$. Oximeters are now available as a small, portable, and inexpensive device that can measure $\mathrm{SpO}_{2}$ at home. Smartphone apps are being developed so that oximeter readings can be downloaded (using a Bluetooth connection) to the phone and shared with providers. While inaccurate oxygen saturation readings are possible due to incorrect finger placement, nail polish, cold fingers, anemia, or device quality, pulse oximeters may be a valuable screening device for COVID19 in acute and non-acute settings (25).

Detecting $\mathrm{AH}$ is critical for the prevention of infection progression and initiating treatment. Earlier interventions could help patients avoid highly invasive procedures (i.e., intubation and mechanical ventilation) and improve the allocation of scarce healthcare resources (25). One pulse oximetry study using a cutoff of $\mathrm{SpO}_{2}$ of $92 \%$ decreased the need for hospitalization for COVID-19 positive patients. Checking their $\mathrm{SpO}_{2}$ regularly provided patient reassurance and reduced emergency room visits (26). The absence of shortness of breath in an older adult should not be considered to be a good sign. In these patients, pulse oximetry is an important means to improve COVID-19 outcomes (20).

\section{COVID-19 SCREENING AND OLDER ADULTS}

Across the nation, testing continues to be inadequate, and temperature screening remains the primary initial objective assessment for COVID-19. The recognition of atypical presentations of infection and physiological aging changes in older adults requires us to implement additional methods of screening to guide clinical decision making.

The diminished febrile response in older adults is a serious disadvantage and suggests fever thresholds should be decreased (9). The absence of shortness of breath in an older adult with comorbidities should not be considered as a sign of well-being. The poor prognoses of asymptomatic hypoxia underscores the severity of this clinical presentation (20). As the absence of fever does not always rule out the presence of an infection, could the screening for "silent hypoxia" help identify older adults with COVID-19 pneumonia earlier? If so, intervening sooner could potentially decrease mortality rates, before the infection progresses to a point of a fever, and the COVID-19 battle is lost. 
Halting the spread of the virus among older adults is a challenge, especially in settings where it may be difficult to quarantine, implement social distancing and encourage cognitively impaired older adults to wear masks (27). As screening is essential; decreasing fever thresholds and adding $\mathrm{AH}$ screening via a pulse oximeter to routine vital signs is not an unrealistic nor cost prohibitive goal.

\section{FINAL REFLECTIONS}

Symptom-based screening for COVID-19 is a less than precise endeavor, and data being collected during this pandemic is finding that temperature and self-report of exposure and/or symptoms are missing more than $50 \%$ of infected individuals (28). Research is needed to determine the most appropriate

\section{REFERENCES}

1. Callahan A, Steinberg E, Fries JA, Gombar S, Patel B, Corbin CK, et al. Estimating the efficacy of symptom-based screening for COVID-19. NPJ Digi Med. (2020) 3:95. doi: 10.1038/s41746-020-0300-0

2. Antonio-Villa NE, Bello-Chavolla OY, Vargas-Vazquez A, Fermin-Martinez CA, Marquez-Salinas A, Pisanty-Alatorre J, et al. Assessing the burden of COVID-19 amongst healthcare workers in Mexico City: a data-driven call to action. medRxiv [preprint]. (2020) 1-25. doi: 10.1101/2020.07.02.20145169

3. Aronson L. Age, complexity, and crisis - a prescription for progress in pandemic. New Engl J Med. (2020) 383:4-6. doi: 10.1056/NEJMp2006115

4. Centers for Disease Control and Prevention Severe Outcomes Among Patients with Coronavirus Disease 2019. (COVID-19). (2020). Available online at: https://www.cdc.gov/mmwr/volumes/69/wr/mm6912e2.htm (accessed November 16, 2020).

5. Ogoina D. Fever, fever patterns and diseases called 'fever' - a review. J Infect Pub Health. (2011) 4:108-24. doi: 10.1016/j.jiph.2011.05.002

6. Shahid Z, Kalayanamitra R, McClafferty B, Kepko D, Ramgobin D, Patel R, et al. COVID-19 and older adults: what we know. J Am Geriatr Soc. (2020) 68:926-9. doi: 10.1111/jgs.16472

7. Farojeh A, Alpert EA, Lipschuetz A, Zalut T, Zimmerman D. Complaints of fever in the elderly in urgent care: pay attention! J Med Emerg Surg Trauma Stress. (2018) 2018:01-5. doi: 10.33513/MEST/1801-01

8. Lu S, Leasure AR, Dai Y. A systematic review of body temperature variations in older people. J Clin Nurs. (2010) 19:4-16. doi: 10.1111/j.1365-2702.2009.02945.x

9. Blatteis CM. Age-dependent changes in temperature regulation- a mini review. Gerontology. (2012) 58:289-95. doi: 10.1159/000333148

10. Obermeyer Z, Samra JK, Mullainathan S. Individual differences in normal body temperature: longitudinal big data analysis of patient records. BMJ. (2017) 359:J5468. doi: 10.1136/bmj.j5468

11. Waalen J, Buxbaum JN. Is older colder or colder older? The association of age with body temperature in 18,630 individuals. J Gerontol A Biol Med Sci. (2011) 66A:487-92. doi: 10.1093/gerona/glr001

12. Falsey AR, Baran A, Walsh EE. Should clinical case definitions of influenza in hospitalized older adults include fever? Influenza Other Respir Viruses. (2019) 9:23-9. doi: 10.1111/irv.12316

13. Leung C. Risk factors for predicting mortality in elderly patients with COVID-19: a review of clinical data in China. Mech Ageing Dev. (2020) 188:111255. doi: 10.1016/j.mad.2020.11 1255

14. Lam P, Coleman BL, Green K, Powis J, Richardson D, Katz K, et al. Predictors of influenza among older adults in the emergency department. BMC Infect Dis. (2016) 16:615. doi: 10.1186/s12879-016-1 966-4 screening assessments for various infectious diseases and the cohorts exhibiting variations from standard physiological norms.

Clinical presentations and physiological differences in older adults should compel healthcare providers to reconsider current assessment and treatment algorithms. For our most diverse population with considerable variations in illness presentations and disease courses, more appropriate and faster clinical decision making is required. No assumptions should be made that a poor prognosis is part of aging when improvements in public health screening may be achieved and the mortality rate of COVID-19 may be reduced or eliminated.

\section{AUTHOR CONTRIBUTIONS}

CV developed the concept of the article and wrote the manuscript. DE consulted on content and edited the manuscript.

15. Hartman L, Zhu Y, Edwards KM, Griffin MR, Talbot HK. Underdiagnosis of influenza virus infection in hospitalized older adults. J Am Geriatr Soc. (2018) 66:467-72. doi: 10.1111/jgs.1 5298

16. Smith BJ, Price DJ, Johnson D, Garbutt B, Thompson M, Irving LB, et al. Influenza with and without fever: clinical predictors and impact on outcomes in patients requiring hospitalization. Open Forum Inf Dis. (2020) 7:ofaa268. doi: 10.1093/ofid/ofaa268

17. Gan JM, Kho J, Akhunbay-Fudge M, Choo HM, Wright M, Batt F, et al. Atypical presentation of COVID-19 in hospitalised older adults. Irish J Med Sci. (2020) 1-6. doi: 10.1007/s11845-020-02372-7. [Epub ahead of print].

18. Nguyen C, Kaku S, Tutera D, Kuschner WG, Barr J. Viral respiratory infections of adults in the intensive care unit. $J$ Intensive Care Med. (2016) 31:427-41. doi: 10.1177/088506661558 5944

19. Levitan R. The Infection That's Silently Killing Coronavirus Patients. New York Times (2020). Available online at: https://www.nytimes.com/2020/04/ 20/opinion/sunday/coronavirus-testing-pneumonia.html (accessed April 30, 2020).

20. Brouqui P, Amrane S, Million M, Cortaredona S, Parola P, Lagier JC, et al. Asymptomatic hypoxia in COVID-19 is associated with poor outcome. Int J Infect Dis. (2020) 102:233-8. doi: 10.1016/j.ijid.2020.10.067

21. Galwankar SC, Paladino L, Gaieski DF, Nanayakkara KDPWB, Di Somma $\mathrm{S}$, Grover J, et al. Management algorithm for subclinical hypoxemia in coronavirus disease-2019 patients: intercepting the "silent killer". J Emer Trauma Shock. (2020) 13:110. doi: 10.4103/JETS.JETS_72_20

22. Jouffroy R, Jost D, Prunet B. Prehospital pulse oximetry: a red flag for early detection of silent hypoxia in COVID-19 patients. Crit Care. (2020) 24:313. doi: 10.1186/s13054-020-03036-9

23. Wilson IH. Pulse oximetry in low-resource settings during the COVID-19 pandemic. Lancet. (2020) 8:e1121-2. doi: 10.1016/S2214-109X(20)30287-4

24. Gupta RK, Marks M, Samuels TH, Luintel A, Rampling T, Chowdhury H, et al. Systematic evaluation and external validation of 22 prognostic models among hospitalised adults with COVID-19: an observational cohort study. Eur Respir J. (2020) 56:2003498. doi: 10.1101/2020.07.24.20149815

25. Teo J. Early detection of silent hypoxia in Covid-19 pneumonia using smartphone pulse oximetry. J Med Syst. (2020) 44:134. doi: 10.1007/s10916-020-01587-6

26. Shah S, Majmudar K, Stein A, Gupta N, Suppes S, Karamanis M, et al. Novel use of home pulse oximetry monitoring in COVID-19 patients discharged from the emergency department identifies need for hospitalization. Acad Emerg Med. (2020) 27:681-92. doi: 10.1111/acem.14053

27. Arons MM, Hatfield KM, Reddy SC, Kimball A, James A, Jacobs JR, et al. Presymptomatic SARS-CoV-2 infections and transmission in a skilled nursing facility. N Engl J Med. (2020) 382:2081-90. doi: 10.1056/NEJMoa2008457 
28. Gostic K, Gomez AC, Mummah RO, Kucharski AJ, Lloyd-Smith JO. Estimated effectiveness of symptom and risk screening to prevent the spread of COVID19. Elife. (2020) 9:e55570. doi: 10.7554/eLife.55570

Conflict of Interest: The authors declare that the research was conducted in the absence of any commercial or financial relationships that could be construed as a potential conflict of interest.
Copyright (C) 2021 Van Son and Eti. This is an open-access article distributed under the terms of the Creative Commons Attribution License (CC BY). The use, distribution or reproduction in other forums is permitted, provided the original author(s) and the copyright owner(s) are credited and that the original publication in this journal is cited, in accordance with accepted academic practice. No use, distribution or reproduction is permitted which does not comply with these terms. 